- $35 \%$ had no increase or decrease in SE, despite being in the job for around 6 months

- $55 \%$ of those with no increase or decreased SE had moderate to intense IP thoughts.

Conclusions Conclusions at this point are tentative, yet of interest. Awareness of mental health and welfare is integral for safe and supported working. In the first study of its kind in the UK, the findings confirm the presence of impostor phenomena in newly qualified doctors. In addition, exploration of changes in self-efficacy as a potential concomitant to the more severe forms of IP, may be worthwhile. Such changes, linked to competency beliefs, may be a more socially acceptable way of engaging in learning supports those doctors in training most at risk of intense impostor phenomena.

\section{G408(P) A PEER LED REFLECTIVE DEBRIEFING PILOT PROJECT}

SM Harris, EM Nickerson. Paediatrics, Aneurin Bevan Heath Board, Newport, UK

\subsection{6/archdischild-2020-rcpch.351}

Aim To evaluate the experience paediatric trainees had of debriefing sessions following resuscitations and to improve access and experience of debriefing sessions by the implementation of peer led reflective debriefing sessions for paediatric staff.

Method An online questionnaire was circulated to all paediatric trainees in Wales. A pilot reflective debriefing project was implemented using the MEDical Trauma Resilience Management (MedTRiM) model. The MedTRiM model is adapted from the TRiM model used in the Royal Marines. It is a proactive, peer delivered, cognitively based and evidence based human resource management initiative for supporting individuals following exposure to potentially traumatic events and including a psychological scoring system for attendees. Ground rules and onward referral mechanisms were identified. Monthly hour long sessions were arranged over a 6 month period. A MedTRiM training course was organised to ensure sustainability and recruit faculty. Cases were referred by consultant of the week and staff invited via email.

Results Our survey of Paediatric trainees in Wales from January 2015, enquiring about experience of debriefing following paediatrics resuscitations, showed that $82 \%$ had been involved with child deaths. Only $17 \%$ had been invited to a debrief $>75 \%$ of the time and no debriefing had been offered $52 \%$ of the time. $57 \%$ said they would have benefited for psychological well being.

During the pilot project, four new clinical cases and one case follow up meeting were planned over the six month period. 34 people were invited with a total of 15 staff attending, across departments and disciplines. No one scored above the threshold for referral. Feedback included the benefits of meeting other team members after the event, having the time set aside to share the emotional impact and becoming aware that their feelings were 'normal' reactions.

Conclusion Following on from the pilot, improvements noted include: having a more robust case reporting system; improved documentation of contact details of those present at the resuscitation; ad hoc meetings rather than regular monthly meetings due to the time lag; and protected time being prioritised for these sessions. Further training courses and establishing a peer support group are planned.

\section{G409(P) A PILOT STUDY PROVIDING VULNERABLE CHILDREN ENTERING EMERGENCY FOSTER CARE WITH BACKPACKS OF ESSENTIAL ITEMS}

${ }^{1} \mathrm{CE}$ Strauss, ${ }^{2} \mathrm{G}$ Hann. ${ }^{1}$ Paediatrics, North Middlesex Hospital, London, UK; ${ }^{2}$ Paediatric Accident and Emergency, North Middlesex Hospital, London, UK

\subsection{6/archdischild-2020-rcpch.352}

Background Our hospital serves a population with some of the greatest deprivation in the UK. Children often attend with acute safeguarding concerns. We estimated 30 children per year are discharged to emergency foster car

Aims

- To provide these children with backpacks of essential and comforting items to help make this experience slightly less terrifying.

- To quantify the need for these backpacks.

- To collect feedback for quality improvement purposes.

Methods With trust funding and charitable donations we created backpacks for all ages and genders. The contents, advised by looked after children, included pyjamas, underwear, toiletries with age appropriate toys and gifts. Demographics and reasons for receiving backpacks were recorded on an excel database. Feedback was on a formal proforma and through observation and conversation.

Results Over 18 months, 56 children's backpacks were distributed (table 1), a larger number than predicted. The cost was $£ 2050$ (average $£ 36.60$ per backpack). Table 1 shows recipient numbers by age and gender.

\begin{tabular}{llll}
\multicolumn{2}{l}{ Abstract G409(P) Table 1 } & & \\
\hline & Male & Female & Unrecorded \\
\hline Newborn & 7 & 7 & 9 \\
$<3$ & 1 & 4 & 1 \\
$3-7$ & 6 & 4 & 1 \\
$8-12$ & 4 & 7 & 1 \\
$13-16$ & & 4 & \\
$>16$ & & & \\
\hline
\end{tabular}

Feedback has been almost universally positive:

'An amazing idea and will mean that children won't have to enter care with nothing which is often the case.' Police

'It brought a smile to my daughter's face' Mother

'It's like Christmas all over again' Teenage boy

'Their face lit up' Nurse

Several neonatal bags were given as the mothers were destitute. Children of three mothers fleeing domestic abuse also received them. Recipients aged 16+ years, include a 23-yearold who was trafficked and pregnant, and a 17 -year-old with learning difficulties, also pregnant and fleeing physical and sexual assault.

Discussion A large international company has taken on fundraising for this project, expanding it to major hospitals in other cities with our assistance.

There is notable overlap of vulnerable children and adults, particularly through trafficking, destitution and domestic abuse. Approximately 3 women a week present through our $\mathrm{A}+\mathrm{E}$ requiring emergency accommodation due to domestic violence or trafficking. We have accordingly extended our project to provide them with similar backpacks. Contents include oyster 